\title{
Atividades de estatística para o 8ㅇ ano do ensino fundamental: algumas considerações
}

Rúbia Juliana Gomes Fernandes rufernandes@hotmail.com 0000-0002-5473-9391 Universidade Tecnológica Federal do Paraná Instituição de Ensino Ponta Grossa, Paraná, Brasil.

\section{Willian Damin}

daminmatematica@hotmail.com 0000-0002-6795-9772

Universidade Tecnológica Federal do Paraná Instituição de Ensino Ponta Grossa, Paraná, Brasil.

\section{Guataçara dos Santos Júnior} guata@utfpr.edu.br

Universidade Tecnológica Federal do Paraná Instituição de Ensino Ponta Grossa, Paraná, Brasil.

\section{RESUMO}

Apresentam-se, neste artigo, resultados de uma investigação que analisou as contribuições de uma atividade dirigida para o ensino de Estatística, nos anos finais do ensino fundamental. Com o intuito de alcançar tal objetivo foram sistematizadas atividades dirigidas, enfocando alguns conteúdos básicos de Estatística, em uma turma de alunos do oitavo ano do ensino fundamental, de uma escola da rede pública de ensino de Curitiba. A base metodológica utilizada foi a pesquisa aplicada, descritiva e os resultados foram analisados na perspectiva qualitativa. Neste estudo, tratou-se de questões pertinentes ao ensino da Estatística, explorando os dados e informações advindas dos estudantes. Constatou-se, durante o trabalho, interesse e predisposição dos alunos para os conteúdos sistematizados. Ao analisar os resultados do desempenho dos alunos durante a execução dessa proposta pedagógica, percebeu-se um avanço quanto à aquisição dos conteúdos envolvendo os conhecimentos voltados à Estatística.
\end{abstract}

PALAVRAS-CHAVE: Educação Estatística. Ensino de Estatística. Ensino e aprendizagem. 


\section{INTRODUÇÃO}

Frente às enormes transformações vivenciadas pela humanidade no final do século XX e início do XXI, em função do fluxo contínuo de informações que circulam através dos diversos contextos sociais, e aos avanços tecnológicos, a Estatística passou a exercer forte influência no tratamento e comunicação dos dados, destacando assim, o aumento de pesquisas que se relacionam com essa área. Já na década de oitenta, estudiosos alertavam que, para ser um cidadão letrado, o sujeito necessitaria de habilidades para ler, calcular, pensar e fazer conjecturas a respeito das informações a ele apresentadas (RUNBERG; MASON, 1988). Analisando este contexto hoje, entende-se que para exercer cidadania plena, as pessoas precisam ter construído o seu pensamento estatístico, sendo ele tão essencial como a habilidade de ler e escrever.

Lopes (1998, 2003, 2008), em suas investigações acadêmicas, continua há quase três décadas à frente, destacando a importância de um trabalho pedagógico efetivo, no que trata dos conhecimentos de Estatística no campo educacional, uma vez que as pessoas estão expostas às informações estatísticas diariamente. Diversas informações veiculadas pela mídia podem influenciar decisões importantes que, por muitas vezes, pela ausência ou fragilidade de conhecimento na área, são aceitas e incorporadas como verdades, tornando o cidadão vulnerável a interpretações errôneas que não expressam a realidade.

A educação escolar pode ser uma grande aliada nesse processo de esclarecimento das pessoas, pois busca formar cidadãos críticos, voltados às demandas sociais atuais. Para isso, objetiva que todos os alunos tenham subsídios para desenvolver habilidades para a vida social contemporânea, de forma que eles possam posicionar-se de maneira significativa em seu meio social. Essa tentativa busca oportunizar a aquisição de conhecimentos estatísticos necessários para o entendimento de diversas informações disponíveis na sociedade, bem como o de atender às recomendações dos documentos oficias que norteiam o ensino de Matemática no Brasil e no Paraná.

Portanto, o objetivo deste artigo é apresentar os resultados de uma investigação que analisou as contribuições de uma atividade dirigida para o ensino de Estatística, nos anos finais do ensino fundamental, para o desenvolvimento dos alunos, quando estimulados a coletar, tratar e comunicar dados. Assim, nessa perspectiva, são descritos os aspectos da Educação Estatística que sustentam a investigação aqui apresentada, de forma a justificar a importância do tema em sala de aula para o desenvolvimento da criticidade pelo aluno.

\section{EDUCAÇÃO ESTATÍSTICA}

A literatura em Educação Estatística sugere que para romper o "hiato 
sentidos outros das coisas, dos fatos, dos fenômenos, e desarmá-los" (CASTRO; CAZORLA, 2007, p.47).

Dessa forma, entende-se que a educação acadêmica, com relação à Estatística pode favorecer o papel das instituições escolares, que é o de preparar os alunos para a vida em sociedade, à medida que oferece uma prática educativa significativa que oportuniza a elaboração de questões em devolutiva a investigações propostas, ao incitar a delimitação de conjecturas, formulação de hipóteses, estabelecimento de relações e implicações na efetivação da problemática a ser resolvida. (LOPES, 1998).

As práticas pedagógicas, nesse contexto, devem promover a descoberta por meio de explorações sistematizadas, viabilizando o processo de compreensão e aquisição dos conceitos estatísticos que favoreçam a sua leitura e entendimento de mundo, pautando-os nos conhecimentos científicos. Sob esse aspecto, acredita-se imprescindível que as instituições escolares oportunizem aos alunos, já desde os primeiros anos de escolarização, a formação desses conceitos que favoreçam o exercício da cidadania.

Cazorla (2005) indica que o ensino da Estatística não deve ser sistematizado numa concepção tradicionalista, ou seja, por meio de um conjunto de técnicas e procedimentos operatórios, bem como não deve limitar-se apenas à coleta de dados ou à mera resolução de exercícios dos livros didáticos. Embora se deva perpassar por tais questões, é indispensável extrapolar exclusivamente essa linha de atuação pedagógica, observando as situações reais que devem significar aos alunos, fonte dos conhecimentos estatísticos.

A dinâmica docente deverá ultrapassar as paredes da sala de aula, contextualizando o que foi construído no âmbito científico e tecnológico, permitindo "aos alunos compreenderem que tal conhecimento não foi algo construído linearmente e que resultou das necessidades que as pessoas tinham em dominar a natureza" (PINHEIRO, 2005, p. 79). Com isso, entende-se ser possível contribuir para tornar os alunos agentes ativos das suas próprias aprendizagens, significando-as num contexto real.

Lopes (1998, p. 11-12), ao discorrer sobre a temática, afirma que o "ensino de Estatística e Probabilidade são conhecimentos fundamentais para analisar índices de custo de vida, para realizar sondagens, escolher amostras e outras situações do cotidiano". Destaca-se que a Probabilidade é uma maneira de mensurar a incerteza e matematizá-la, favorecendo a aplicação dos conceitos em situações-problemas reais dos indivíduos ou artificiais para a experimentação (LOPES, 1998).

Coutinho (2009) menciona que, para sistematizar os conceitos e procedimentos com os alunos da Educação Básica, é essencial permitir vivenciar, efetivamente, os processos de experimentação científica do ponto de vista do desenvolvimento do raciocínio probabilístico.

Nesta perspectiva, o fio condutor com relação à aprendizagem matemática é tentar possibilitar a estruturação e o desenvolvimento do trabalho didático-pedagógico da Estatística no ambiente escolar, pois se 
compreende que, do mesmo modo que a matemática se desenvolveu a partir da necessidade dos indivíduos em resolver problemas de ordem prática, os conceitos probabilísticos e estatísticos seguiram a mesma lógica.

É fundamental fazer a distinção entre situações-problemas e exercícios de aplicação de conceitos de Estatística e Probabilidade previamente sistematizados, pois a constituição de uma situação-problema abarca elementos mais elaborados do que simplesmente a aplicação direta e imediata desses conceitos e envolverá a interpretação e o estabelecimento de estratégias para resolvê-la. Pozo (2000) indica que, para solucionar uma situação-problema em âmbito matemático, devem ser utilizadas todas as informações e conhecimentos relacionados à questão.

Nesse sentido, Lopes (2008, p. 62) declara:

[...] não faz sentido trabalharmos atividades envolvendo conceitos estatísticos e probabilísticos que não estejam vinculados a uma problemática. Propor coleta de dados desvinculada de uma situação-problema não levará à possibilidade de uma análise real. Construir tabelas e gráficos desvinculados de um contexto ou relacionados a situações muito distantes do aluno podem estimular a elaboração de um pensamento, mas não garantem o desenvolvimento de sua criticidade.

Entende-se que não basta desenvolver um processo de ensino fora de um contexto problematizado real que oportunize reflexões sobre conceitos probabilísticos e estatísticos, uma vez que é fundamental que o estudante pense sobre o problema e tenha subsídios para solucioná-lo a partir de seu contexto.

Isso, também, não significa somente sistematizar pedagogicamente os conceitos do senso comum que o aluno traz de seu convívio social. Deve-se aproveitá-los, para torná-los científicos, vislumbrando contribuir para que os indivíduos, gradativamente, se posicionem reflexivamente diante das atividades de ensino, tendo em vista que estas situações já se apresentam para o aluno, com um mínimo de familiaridade e conhecimento.

A esse respeito, pensando em contribuir com o processo de criticidade dos indivíduos e com o exercício pleno de sua cidadania, Lopes (2008, p.6061) faz a seguinte afirmação:

Não basta ao cidadão entender as porcentagens expostas em índices estatísticos como o recenseamento populacional, taxas de inflação, desemprego, é preciso analisar/relacionar criticamente os dados apresentados, questionando/ponderando até mesmo sua veracidade. Assim como não é suficiente ao aluno desenvolver a capacidade de organizar e representar uma coleção de dados, faz-se necessário interpretar e comparar esses dados para tirar conclusões. 
Cabe destacar que, nos Parâmetros Curriculares Nacionais (BRASIL, 1997), o currículo da Matemática pretende oportunizar condições para que o aluno ultrapasse uma forma particular de compreender seu contexto social e torne-se agente ativo de mudanças. Portanto, fica evidente que o trabalho pedagógico adequado ocupa papel de destaque nessa perspectiva, pois cabe a ele viabilizar os processos educativos referentes à Educação Estatística.

Lopes (2008) destaca que, para facilitar a interpretação dos resultados, o processo de tomada de decisão e a retirada de conclusões, as atividades devem ser vinculadas ao cotidiano dos próprios alunos, levando em consideração a importância da sua problematização.

Ratifica-se, portanto, a necessidade de se articular a Educação Estatística com o processo de resolução de problemas com significado, levando em conta a formação de conceitos, a criação e a apropriação de procedimentos e a aquisição de atitudes frente à necessidade de raciocinar probabilística e estatisticamente (ESTEVAM, 2010, p. 36).

O Guidelines for Assessment and Instruction in Statistics Education (GAISE) Report: a Pré-K-12 Curriculum Framework propõe que a resolução de problemas estatísticos, no entendimento dos pesquisadores, siga um ciclo investigativo, envolvendo quatro componentes:

I. Formulação de Questões: a) esclarecimento do problema em mãos; b) formulação de questões que possam ser respondidas com os dados.

II. Coleta de Dados: a) elaboração de um plano apropriado de coleta de dados; b) utilização do plano para a coleta de dados.

III. Análise dos Dados: a) escolha de métodos gráficos e numéricos apropriados; b) utilização desses métodos para analisar os dados.

IV. Interpretação dos Resultados: a) interpretação das análises; b) relacionamento da interpretação com a questão inicial.

Nesse contexto, a estrutura conceitual para a Educação Estatística, seguida nesta investigação, é apresentada no Quadro 1. Destaca-se que foram excluídos os Níveis B e C, por não se constituírem em focos do trabalho.

Quadro 1: Modelo da estrutura conceitual em Educação Estatística

\begin{tabular}{|c|l|}
\hline $\begin{array}{c}\text { Componente do } \\
\text { processo }\end{array}$ & \multicolumn{1}{|c|}{ Nível A } \\
\hline $\begin{array}{c}\text { I. Formulação da } \\
\text { Questão }\end{array}$ & $\begin{array}{l}\text { Início da conscientização da distinção de } \\
\text { questões estatísticas. Os professores propõem } \\
\text { questões de interesse. As questões são restritas à } \\
\text { sala de aula. }\end{array}$ \\
\hline II. Coleta de Dados & $\begin{array}{l}\text { Ainda não se concebe a existência de diferenças. } \\
\text { Censo de sala de aula. Experimentos simples. }\end{array}$ \\
\hline
\end{tabular}




\begin{tabular}{|c|l|}
\hline III- Análise de Dados & $\begin{array}{l}\text { Utilizar propriedades particulares de } \\
\text { distribuições no contexto de um exemplo } \\
\text { específico. Mostra variabilidade dentro de um } \\
\text { grupo. Compara indivíduo para indivíduo. } \\
\text { Compara indivíduos com o grupo. Início da } \\
\text { consciência de grupo para grupo. Observa } \\
\text { associação entre duas Variáveis. }\end{array}$ \\
\hline IV. Interpretação dos & $\begin{array}{l}\text { Os alunos não olham para além dos dados. Não } \\
\text { generalizam para além da sala de aula. Notam } \\
\text { Resultados } \\
\text { diferença entre dois indivíduos com diferentes } \\
\text { condições. Observam associação em displays. }\end{array}$ \\
\hline
\end{tabular}

Fonte: Adaptado de ASA (2005)

Nesta pesquisa, o intuito é de alcançar o Nível A proposto pelo GAISE, de forma que os outros níveis possam ser desenvolvidos em pesquisas de maior duração. Nesse contexto, o objetivo aqui é apresentar as fases desenvolvidas na pesquisa e relatar os achados, contribuindo assim, com a Educação Estatística e testando as teorias nessa área.

\section{ENCAMINHAMENTOS E PROCEDIMENTOS METODOLÓGICOS}

Os participantes da pesquisa foram 33 alunos de uma turma do oitavo ano do Ensino Fundamental, de uma escola da Rede Municipal de Curitiba. A base metodológica utilizada foi a pesquisa aplicada, descritiva e os resultados foram analisados na perspectiva qualitativa. O conjunto de dados coletados para esse estudo é composto por anotações realizadas pelos pesquisadores, atividades realizadas pelos alunos e registros fotográficos.

Para realização da pesquisa, aplicou-se uma sequência de atividades dirigidas, objetivando sistematizar o ensino de Estatística, nos anos finais do Ensino Fundamental. Para a aplicação dessas atividades foram organizadas cinco aulas de 50 minutos cada uma, divididas em três encontros, na disciplina de Matemática. Os encontros estruturaram-se da seguinte forma:

$1^{\circ}$ Encontro: Delineando a temática coletivamente.

$2^{\circ}$ e $3^{\circ}$ Encontro: Coleta, análise e sistematização dos dados.

$4^{\circ}$ e $5^{\circ}$ Encontro: Representação dos dados.

Durante a aplicação das atividades dirigidas, foram percebidos elementos essenciais nas atitudes dos alunos, como: motivação, disposição, interesse e persistência na tentativa de responder as problemáticas elencadas, bem como a análise, o entendimento e a valorização do trabalho coletivo (BRASIL, 1997). Além disso, foi possível identificar os conhecimentos, dificuldades e defasagens, no que trata do conteúdo curricular de Estatística. 
Descreve-se aqui o ciclo das atividades trabalhadas com os alunos em sala de aula de acordo com GAISE (ASA, 2005).

Primeiro Encontro: Delineando a temática coletivamente.

Para começar a sistematização didática optou-se em realizar uma roda de conversas para que os alunos tivessem a possibilidade de elencar temáticas coletivas interessantes para a turma.

Os alunos se organizaram em grupos para pensar e discutir alguns assuntos que gostariam de apresentar, analisar e estudar, sob a ótica dos conhecimentos estatísticos, para posterior sistematização em sala de aula. Nesse momento, alguns itens sugeridos pelos alunos e pesquisador foram apresentados, como: time de futebol e esporte preferido, jogos eletrônicos e tabuleiros, utilização de redes sociais, disciplina predileta, entre outras. A partir desse dialogo coletivo, a opção da turma foi por jogos.

Nesse primeiro encontro, acredita-se estar contribuindo para o desenvolvimento do aluno enquanto comunicador de suas opiniões e suas escolhas, sendo que Brasil (1997) propõe que seja desenvolvida essa atitude em sala de aula. Foi notório que, ao existir a discussão e reflexão coletiva sobre os temas, e o porquê das escolhas, os alunos aprenderam a falar e ouvir, apresentar suas ideias, além de respeitar a dos outros, sob um olhar crítico.

Na concepção de Bakthin (1992, p. 123), “o diálogo em seu sentido amplo, concebido como toda comunicação verbal de qualquer tipo, é a base da interação social, pois a dialogia implica a existência de sujeitos e a alternância dos locutores". As interações verbais sociais presentes nas relações dialógicas, estabelecidas nos ambientes escolares e, principalmente, em sala de aula, primam pela linguagem, configuram-se como um território de embates e debates constantes. Assim entende-se, que a escola pode ser vista como um espaço de criação e enunciação de ideias, utilizando a linguagem para tal.

Nesse sentido, as interações sociais mediadas pela ação dialógica tornam-se indispensáveis, ao objetivar a construção dos saberes discentes, por meio da prática pedagógica docente interacionista. Ao perceber que o aluno já vem para a escola com conhecimentos e experiências do senso comum, cabe a ela mediar o processo de ensino de conhecimentos científicos, favorecendo ao estudante conflitos cognitivos, de modo que gerem aprendizagens.

Acredita-se possível oportunizar uma aprendizagem efetiva com relação à estatística no processo pedagógico, ou seja, os eixos desencadeadores de conceitos, ideias e métodos estatísticos não devem, unicamente, ser a definição de alguns exercícios de aplicação mecânica e operatória imediatas. Devem ser propostas situações-problemas contextualizadas ou mais familiares possíveis, a exemplo da problemática proposta aos alunos.

Destaca-se a afirmação realizada por Moura (1992, p.51), ao refletir que a "resolução de problemas está intimamente vinculada à intencionalidade do professor", sendo uma postura que deve ser assumida na condução do processo de ensino e aprendizagem. Ao "assumi-la com vistas ao desenvolvimento de conceitos científicos exige um projeto de ensino [...]. 
Fazer isto é dar um sentido humano ao jogo, à resolução de problemas e, sendo assim, à Educação Matemática".

Grando (2004, p. 29) afirma que a prática da resolução de problemas, enquanto "estratégia de ensino evidencia vantagens no processo de criação e construção de conceitos, quando possível, por meio de uma ação comum estabelecida, a partir da discussão matemática entre os alunos, e entre o professor e os alunos".

Segundo e terceiro encontro: Coleta de dados e representação de dados

A turma iniciou o processo de coleta de dados na própria sala de aula. $\mathrm{O}$ primeiro ponto foi relacionar todos os jogos que a turma pontuou. Como a escolha envolveu muitos jogos, foi necessário restringir a quantidade dos mesmos. Foi realizada uma votação para identificar apenas cinco dos jogos propostos. Na sequência, os alunos confeccionaram uma tabela simples, e outra de dupla entrada para representar os dados.

Durante a realização dessa atividade, instigou-se uma discussão envolvendo os elementos que pertencem à estrutura tabular e suas especificidades, além de sua vasta empregabilidade social. A esse respeito, Vendramini, Cazorla e Silva (2009) apresentam os elementos que devem compor qualquer estrutura ou representação tabular:

Título: indica a que se refere a tabela em questão. Deve ser numerado com algarismos arábicos em ordem crescente dentro de um capítulo.

Coluna indicadora: apresenta a variável e seus respectivos valores.

Cabeçalho: tem a função de nomear as variáveis.

Corpo da tabela: forma-se pela interseção de linhas e colunas.

Fonte: indica as fontes de informação.

Entende-se que as tabelas precisam ser autoexplicativas, ou seja, precisam ser claras e objetivas quanto à apresentação de todos os dados fundamentais, sem a necessidade de nenhum contexto textual para serem entendidas.

Contudo, notou-se que grande parte dos alunos não fizeram uma tabela, e sim um quadro. Tal fato pode ser justificado em virtude do aluno conhecer quadro por tabela, talvez por influência de vários livros didáticos que não omitem as linhas, formando assim quadros, e apresentando como tabelas. Também há casos que a omissão de linhas existe, porém, com o fechamento nas laterais, situação que anula a representação em tabela.

Quanto à tabela de dupla entrada, é aquela que apresenta dados conectados a duas variáveis. Nesse caso, pode-se apresentar uma tabela de dupla entrada, ao expressar a escolha dos jogos pelos alunos, por gênero feminino e masculino. O jogo é a variável qualitativa num contexto bivariado, ou seja, o gênero.

Destaca-se, então, para o processo de ensino e aprendizagem, a participação e interação dos discentes nas atividades que envolvam a coleta, o tratamento e a transmissão dos dados estatísticos. É primordial que eles 
tenham condições de refletir e tecer conclusões sobre o processo em sua totalidade. Corrobora-se com o exposto, ao analisar que deve ser o "estudante que busca, seleciona, faz conjecturas, analisa e interpreta as informações para, em seguida, apresentá-las para o grupo, sua classe ou sua comunidade" (WODEWOTZKI; JACOBINI, 2005, p.233). Portanto, acredita-se que atividades direcionadas com esse intuito podem desenvolver gradualmente as competências estatísticas dos alunos. Por isso, entende-se que os alunos ao participarem efetivamente de atividades pedagógicas nesse formato, podem dar significação e ressignificação aos seus conhecimentos estatísticos e colaboração no processo de seus pares.

Quatro e quinto encontro: Representação e interpretação dos resultados

Entende-se que nessa fase, de acordo com Gaise (2005), os alunos tenham condições de interpretar de forma genérica os dados coletados, e que com a ajuda dos conceitos estatísticos sejam capazes de expressar esses dados. Dessa forma, com o intuito de construir um modelo para melhor interpretar os resultados, optou-se pela representação gráfica. Os alunos dirigiram-se ao laboratório de informática para que pudessem apresentar os dados advindos da atividade em sala de aula, utilizando como recurso o excel.

Nessa atividade, os alunos tiveram a oportunidade de visualizar os dados em diversas representações, como: gráficos de barras, colunas, pictogramas, setores entre outras. Percebeu-se que os alunos participantes, a todo o momento, se mostravam empolgados com as atividades desenvolvidas, sempre buscando participar e ajudar na construção dos modelos. Essa característica é proposta por Brasil (1997) ao salientar o desenvolvimento de atitudes e procedimentos. Entende-se que os procedimentos desenvolvidos pelos alunos ajudam a manifestar seus conhecimentos estatísticos. Para concluir, na sequência, em sala de aula, foram explorados os elementos matemáticos necessários para representação manual do gráfico de setores.

\section{CONSIDERAÇÕES FINAIS}

Destaca-se a importância em relatar as experiências vivenciadas em sala de aula, de forma que a leitura de artigos, dissertações e teses, é que disseminam a área da Estatística. Acredita-se ainda, que as leituras podem oportunizar trocas de experiências, mesmo que implicitamente. Assim, resgatando o objetivo deste trabalho, o de apresentar as contribuições da aplicação de uma atividade dirigida, apresenta-se aqui um fechamento deste artigo.

$\mathrm{Na}$ tentativa de interligar o referencial teórico descrito, a atividade dirigida foi dividida em formulação da questão, coleta de dados, análise de dados e interpretação dos resultados. Acredita-se que essas fases aplicadas puderam promover o desenvolvimento de algumas capacidades pelos alunos participantes, dentre elas, destacam-se as atitudes. A todo o momento, observou-se a motivação dos alunos ao trabalharem com os próprios dados coletados, em uma perspectiva diferenciada e não tradicionalista. 
Essa perspectiva adotada revela que as atividades de Estatística podem contribuir para o desenvolvimento pessoal e cognitivo do aluno, visto que eles precisam pensar, raciocinar e interpretar estatisticamente e, ao final da investigação, comunicar os resultados encontrados.

É dessa forma que se acredita estar contribuindo com o aprendizado dos alunos e com a disseminação da Educação Estatística, ao relatar os achados em uma pesquisa que objetivou desenvolver conceitos e conteúdos de Estatística na Educação Básica. 


\title{
STATISTICAL ACTIVITIES FOR 8TH GRADE OF ELEMENTARY SCHOOL: SOME CONSIDERATIONS
}

\begin{abstract}
This article shows results of a research which has analyzed the contributions of a guided activity to the Statistics teaching in the late years of elementary school. In order to reach this goal, it was systematized guided activities, focusing on some basic contents of Statistics, in a class of eighth grade students from a public school in Curitiba. The methodological basis used was applied, descriptive research and the results were analyzed from a qualitative perspective. In this study, questions related to the teaching of statistics were explored, exploring the data and information coming from the students. It was observed, during the research, the student's interest and predisposition to the systematized contents. When analyzing the results of the students' performance during the execution of this pedagogical proposal, it was noticed an improvement in the acquisition of the contents involving the knowledge related to Statistics.
\end{abstract}

Keywords: Statistics Education. Teaching Statistics. Teaching and learning. 


\section{REFERÊNCIAS}

American Statistical Association (ASA). Guidelines for Assessment and Instruction in Statistics Education (GAISE) Report: A Pre-K-12 Curriculum Framework. Alexandria, 2005. disponível em: $<$ http://www.amstat.org/education/gaise/GAISEPreK12_Intro.pdf >. Acesso em: 02 jan. 2016.

BRASIL. Ministério da Educação. Secretaria de Ensino Fundamental. Parâmetros Curriculares Nacionais: ensino fundamental $\left(5^{\mathrm{a}}\right.$ a $8^{\mathrm{a}}$ série)/matemática. Brasília (DF): MEC/SEF, 1998.

CASTRO, F. C.; CAZORLA, I. M. Tratamento da informação na educação básica. In: III CONGRESSO INTERNACIONAL DE ENSINO DE MATEMÁTICA, 3., 2005. Anais... Canoas (RS), Universidade Luterana do Brasil, 2005.

COUTINHO, C. Q. S. Desenvolvimento do pensamento estatístico e sua articulação com a mobilização de registros de representação semiótica. Bolema, Rio Claro (SP), v. 24, n. 39, p. 495-514, ago. 2011.

ESTEVAM, E. J. G. (Res)significando a Educação Estatística no Ensino Fundamental: análise de uma sequência didática apoiada nas Tecnologias de Informação e Comunicação. 2010. Dissertação (Mestrado em Educação) - Universidade Estadual Paulista "Júlio de Mesquita Filho". Presidente Prudente (SP).

GRANDO, R. C. O jogo e a matemática no contexto da sala de aula. São Paulo: Paulus, 2004.

LOPES, C. A. E. A probabilidade e a estatística no ensino fundamental: uma análise curricular. 1998. Dissertação (Mestrado em Educação) Faculdade de Educação. Universidade de Campinas. Campinas (SP).

O conhecimento profissional dos professores e suas relações 
Reflexões teórico-metodológicas para a educação estatística.

CURI; E. (Orgs.). Pesquisas em educação matemática: um encontro entre a teoria e a prática. $1^{\mathrm{a}}$ ed. São Carlos (SP): Pedro \& João Editores, 2008.

MOURA, M. O. O jogo e a construção do conhecimento matemático. São Paulo: FDE, 1992. (Série Ideias, n. 10).

PINHEIRO, M. A. N. Educação crítico-reflexiva para o ensino médio científico-tecnológico: a contribuição do enfoque CTS para o ensinoaprendizagem do conhecimento matemático. 2005. Tese (Doutorado em Educação Científica e Tecnológica) - Universidade Federal de Santa Catarina. Florianópolis (SC).

POZO, J. I. (Org.). A solução de problemas: aprender a resolver, resolver para aprender. Porto Alegre: Artmed, 2000.

RUMBERG, S. J.; MASON, R. L. Increasing public awareness of Statistics as a science and profession starting in high school. The American Statistician, v. 42, n. 3, p. 167-170, 1988.

WODEWOTZKI, M. L. L.; JACOBINI, O. R. A modelagem matemática aplicada no ensino de estatística em cursos de graduação. Bolema, Rio Claro (SP), v.14, p.47-68, 201

DOI: $10.3895 /$ rbect.v10n1.5693

Como citar: FERNANDES, R. J. G.; DAMIN, W.; JÚNIOR, G. DOS S. Atividades de estatística para o $8^{\circ}$ ano do ensino fundamental: algumas considerações. Revista Brasileira de Ensino de Ciência e Tecnologia, $v$. 10, n. 1, 2017. Disponível em: <https://revistas.utfpr.edu.br/rbect/article/view/5693>. Acesso em: xxx.

Direito autoral: Este artigo está licenciado sob os termos da Licença Creative Commons-Atribuição 4.0 Internacional. 